\title{
Incidence of Hemorrhage after ENT Procedures and Seasonal Variation: A Retrospective Study and Literature Review
}

\author{
Loay Alekri ${ }^{\star}\left(\mathbb{D}\right.$, Fatema N. Alfayez ${ }^{\star}$ (i) \\ Otorhinolaringology, Head \& Neck Surgery Department, Salmaniya Medical Complex, Manama, Kingdom of Bahrain \\ Email: loayalekri@gmail.com, f.alfayez.md@gmail.com
}

How to cite this paper: Alekri, L. and Alfayez, F.N. (2021) Incidence of Hemorrhage after ENT Procedures and Seasonal Variation: A Retrospective Study and Literature Review. International Journal of Otolaryngology and Head \& Neck Surgery, 10, 173-183.

https://doi.org/10.4236/ijohns.2021.103018

Received: April 13, 2021

Accepted: May 21, 2021

Published: May 24, 2021

Copyright $\odot 2021$ by author(s) and Scientific Research Publishing Inc. This work is licensed under the Creative Commons Attribution International License (CC BY 4.0).

http://creativecommons.org/licenses/by/4.0/

\section{(c) (i) Open Access}

\begin{abstract}
Background: Ear, nose, throat procedures are the most performed procedures for adults and children per year. Doctors might have noticed that at certain times of the year, there would be an increase in admissions of post tonsillectomy bleeding or epistaxis after nasal surgeries. Objectives: To determine whether a correlation exists between season and the rate of hemorrhage presentation after ear, nose, throat procedures. Methods: A 12-year retrospective review from January of 2003 to June of 2015, involving 1032 patients who developed secondary hemorrhage following ear, nose, throat related surgeries. We analyzed the presentation of hemorrhage in relation to the month of admission. Meteorological data were obtained from the Meteorological directorate of Bahrain. Results: Post-Operative Hemorrhage occurred in (1032) patients. The season and air temperature had a significant influence on secondary post-tonsillectomy hemorrhage and post-septoplasty epistaxis according to the age with a significant increase in their rate during the summer months $(\mathrm{p}<0.05)$. Conclusion: The incidence of hemorrhage showed monthly and seasonal variations. This is clearly a multi-factorial problem. However, in patients at high risk of bleeding, consideration should be given to performing surgeries at a time of year of lower rates.
\end{abstract}

\section{Keywords}

Secondary Post-Tonsillectomy Bleeding, Post-Septoplasty Epistaxis, Seasonal Variation, Bahrain

\section{Introduction}

Ear, nose, throat (ENT) procedures are the most performed procedures for adults

${ }^{\star}$ Two authors contributed equally to this work. 
and children per year [1], therefore they continue to exhibit many post-operative complications. These include pain, hemorrhage, dehydration, and infection. Pain and post-operative bleeding are the most reported causes of readmission. Post tonsillectomy hemorrhage (PTH) occurs in about $0.3 \%-6.1 \%$ of the cases according to previous studies [2] [3], while bleeding following nasal surgeries occurs at a rate of less than $1 \%$ [4]. Causes and risk factors of hemorrhage presentation after ENT procedures vary from a patient to another. The most contributing factors were heavy physical activity, surgical technique, patient age, gender, post-operative analgesic use, and cough [5]-[10]. Increased risk of bleeding was correlated with longer duration of symptoms, lower levels of C-reactive protein, and GAS infection [11]. While the association to infection markers and bacterial findings are previously unexplored, Giger et al. found male gender, smoking, and aspirin intake to be risk factors for PTH following quinsy tonsillectomy [12].

In ancient Greece, it was thought that weather changes could influence human physiological processes [13]. Data regarding the effect of weather on post-tonsillectomy hemorrhage or epistaxis is limited and shows inconsistency. In this study, we aimed to show the association between weather variables and hemorrhage after ENT procedures.

Although there are studies reporting that hemorrhage rate is higher in Summer months, there are also some studies that oppose this theory. This retrospective study has limitation factors, but it was an attempt to analyze common complications, and correlate them with international figures. Additional data may be helpful in explaining the effect of weather on hemorrhage postoperatively which will allow us to perform procedures on patients at a time that carries minimal risk to them.

\section{Methods}

This is a 12-year retrospective cohort study that review data from January of 2003 to June of 2015, involving 1032 patients who developed secondary Post-Operative Hemorrhage (POH). We analyzed the presentation of hemorrhage in relation to the month of admission. Meteorological data were obtained from the Meteorological directorate of Bahrain.

Secondary post-operative hemorrhage is defined as hemorrhage that occurs post 24 hours of surgical procedure like tonsillectomy [14].

Inclusion criteria: all patients operated during the studied period and developed secondary bleeding post ENT procedures (tonsillectomy, adenoidectomy, septoplasty, turbinates surgery, sinus surgery) were enrolled in the study. Exclusion criteria: primary bleeding, or bleeding due to other reasons, and procedures done before 2003 were not included.

Our analysis looked retrospectively at outcomes for a large cohort of patients treated. This was done internally as part of an audit, to improve our quality of care. The findings of seasonal variance and its' relation to $\mathrm{POH}$ is a vital information that should be shared with wider medical community-hence our deci- 
sion to submit our findings to a reputable open source journal. XXXX institutional board review provided us with the ethical approval of this study with approval number of 149-20. No patient consent was required because the study was performed by chart review.

The patient's medical records were reviewed for patient identification number, date of admission, age, and gender. A data collection sheet was used to extract the desired variables in a consistent manner. The patients were divided into two age groups: pediatric ( $\leq 14$ years of age) and adults ( $>14$ years of age). Meteorological division data was used to describe the seasons, rather than the Astronomical division, because the meteorological data are based on the annual temperature cycle. Therefore, each year (2003-2015) was divided into 4 seasons of 3 months each. The cases were classified into four groups depending on the time of operation, i.e. group 1 in the spring (March, April and May), group 2 in the summer (June, July, and August), group 3 in the autumn (September, October and November), and group 4 in the winter (December, January and February). We also divided the months into cold (November-February) and warm (March-October) months for statistical analysis purposes.

Missing patient data was ignored and omitted from the study. By this mean we removed outliers as a means of trimming the data set.

\section{Statistical Analysis}

The retrieved medical data was analyzed using the SPSS program, version 20.0. Quantitative and qualitative variables were conducted in the study including mean \pm standard deviation for quantitative data, frequencies, and percentages for qualitative data. The Chi-squared test was used for analysis of seasonal variations of $\mathrm{POH}$. All tests were done with statistical significance as $(\mathrm{p}<0.05)$.

\section{Results}

In our study we have reported 1032 patients who had $\mathrm{POH}$ following tonsillectomy or nasal surgeries at our institution during the 12 years study period, and all those patients were included in the study. Their ages ranged between 1 and 63 years old, with a mean age of $18.42(+/-12.610)$, male patients were more than females $621(60.2 \%)$ with a male to female ratio of 2.07:1.37 (Table 1). The total number of procedures performed for each individual year is shown in (Figure 1).

When the seasonal distribution of all cases was considered, the rate of hemorrhage peaked in the summer (Table 1, Figure 2). POH significantly increases during the summer months and decreases during the spring months (Table 2). Accordingly, between the summer months and autumn and winter months, there was a reasonable increment in hemorrhage and the difference was statistically significant $(\mathrm{p}<0.05)$ (Table 2). As illustrated in (Figure 3), there was a drop in cases of approximately $30 \%$ from the warmest month to coldest (120 cases in July to 54 cases in December). 


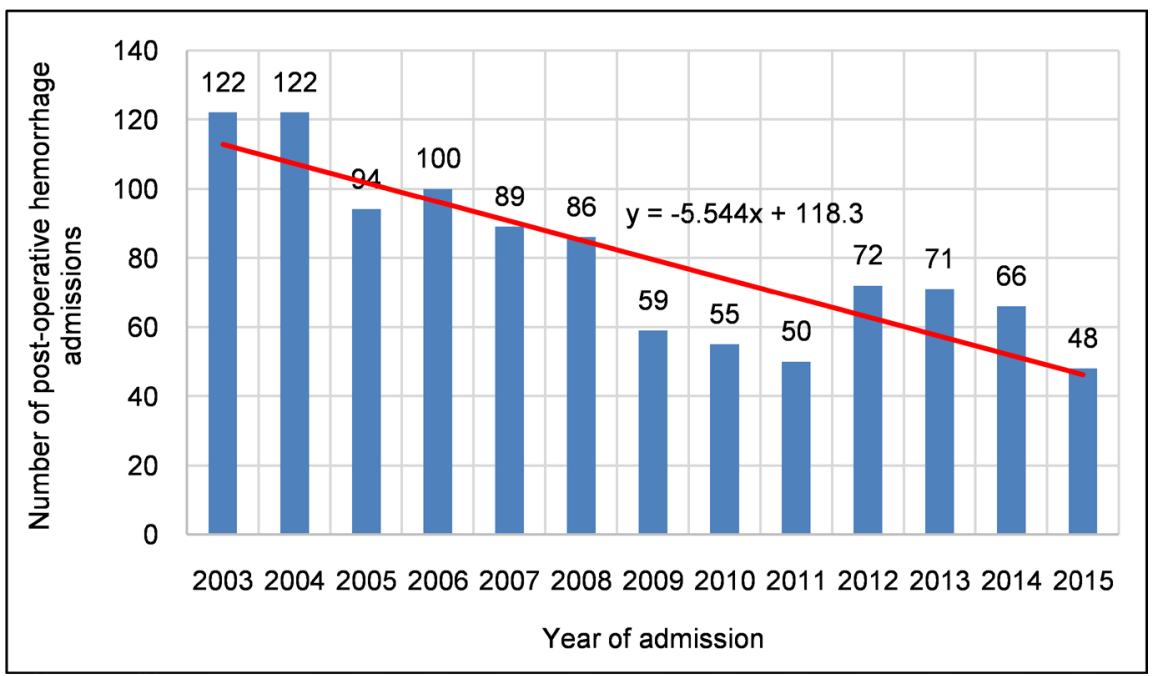

Figure 1. The number of post-operative hemorrhage admissions by year.

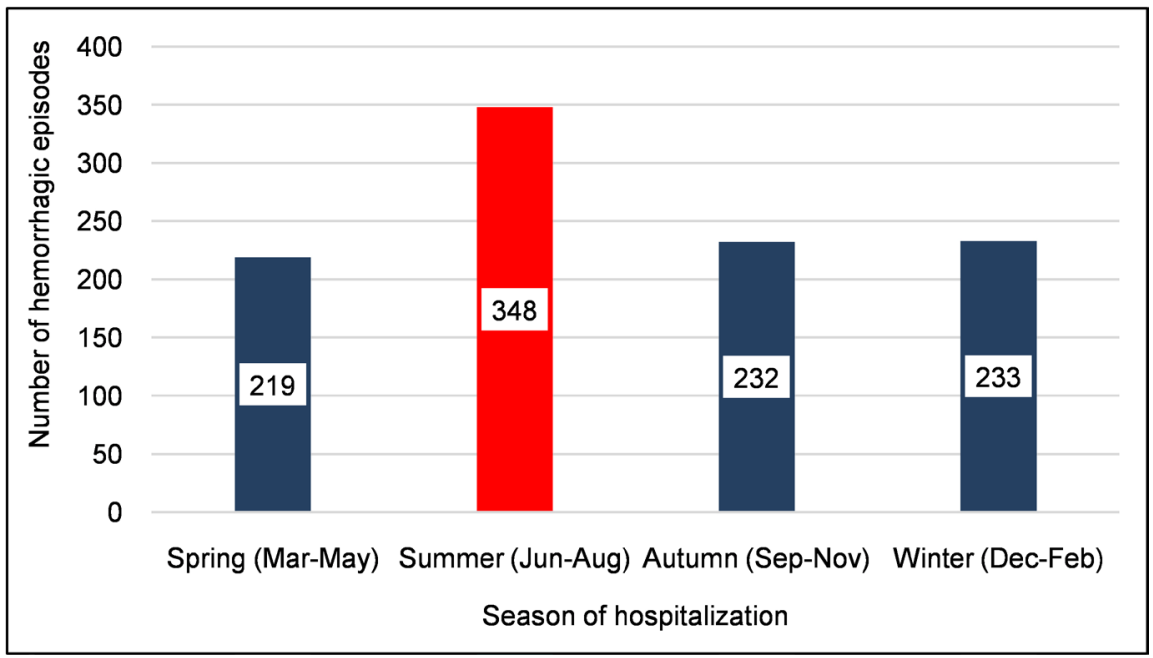

Figure 2. The frequency of post-operative hemorrhage admissions over the season.

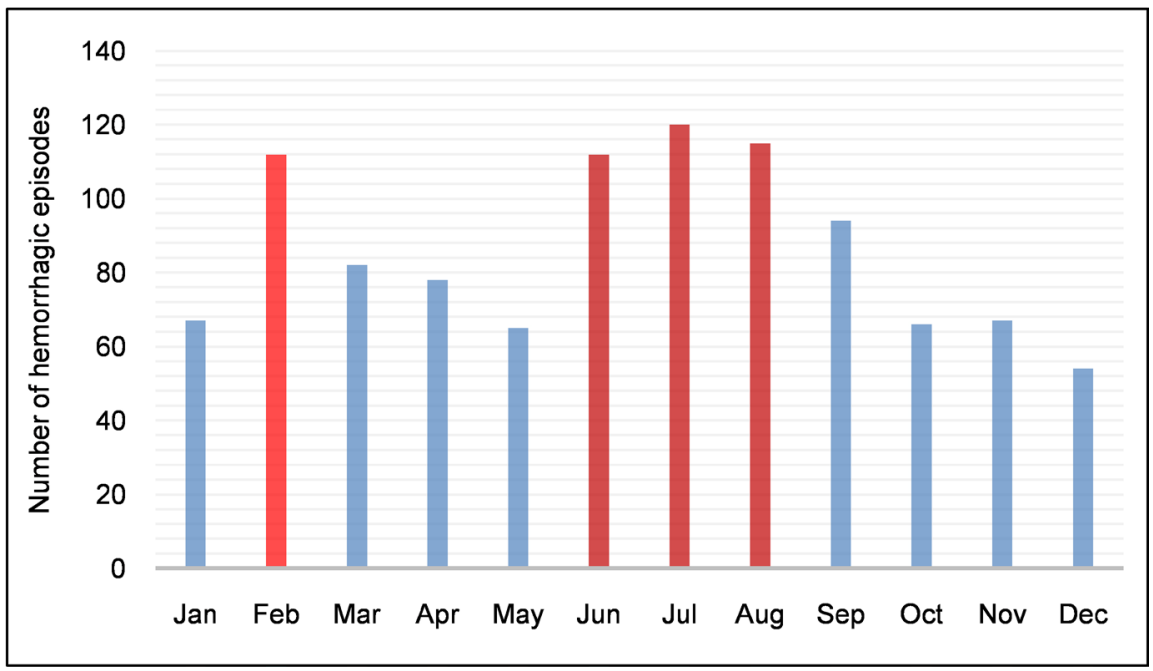

Figure 3. The frequency of $\mathrm{POH}$ admitted cases per month. 
Table 1. Distribution of POH, 2003-2015 by gender, cortical age, and season of hospitalization.

\begin{tabular}{lccc}
\multicolumn{1}{c}{ Parameter } & n & $\%$ & P value \\
\hline Gender & 621 & 60.2 & $<0.0001$ \\
$\quad$ Male & 411 & 39.8 & \\
$\quad$ Female & & & \\
Age $\quad 472$ & 45.7 & \\
$\quad \leq 14$ years & 560 & 54.2 & \\
$\quad \geq 14$ years & & & \\
Season of hospitalization & & & \\
Spring & 219 & 21.2 & \\
Summer & 348 & 33.7 & \\
Autumn & 232 & 22.5 & \\
Winter & 233 & 22.6 & \\
\hline
\end{tabular}

Table 2. Statistical distribution of $\mathrm{POH}$ according to the seasons.

\begin{tabular}{ccccc}
\hline P value* POH & $\begin{array}{c}\text { Group 1 } \\
\text { (Spring) }\end{array}$ & $\begin{array}{c}\text { Group 2 } \\
\text { (Summer) }\end{array}$ & $\begin{array}{c}\text { Group 3 } \\
\text { (Autumn) }\end{array}$ & $\begin{array}{c}\text { Group 4 } \\
\text { (Winter) }\end{array}$ \\
\hline $\begin{array}{c}\text { Group 1 } \\
\text { (Spring) }\end{array}$ & - & $\mathbf{0 . 0 0 1 4}$ & 0.7388 & 0.7195 \\
$\begin{array}{c}\text { Group 2 } \\
\text { (Summer) }\end{array}$ & $\mathbf{0 . 0 0 1 4}$ & - & $\mathbf{0 . 0 0 3 7}$ & $\mathbf{0 . 0 0 4 0}$ \\
$\begin{array}{c}\text { Group 3 } \\
\text { (Autumn) }\end{array}$ & 0.7388 & $\mathbf{0 . 0 0 3 7}$ & - & 0.9794 \\
Group 4 & & & & \\
(Winter) & 0.7195 & $\mathbf{0 . 0 0 4 0}$ & 0.9794 & - \\
\hline
\end{tabular}

The season and air temperature had a significant influence on secondary posttonsillectomy hemorrhage and post-septoplasty epistaxis according to the average age with a significant correlation of $(\mathrm{p}<0.05)($ Table 1$)$. On the other hand, there was no significant relation between seasonal variation and gender $(\mathrm{P}=$ $0.102)$.

The frequency of admissions was mostly at the summer season at the months of June to August with a peak at the month of July, by 347 (33.6\%) patients (Figure 2, Figure 3). Of these the pediatric admissions were 110 (10.7\%) patients, with the highest rate of admission at the age 4 years with 74 (14.4\%) admissions (Figure 4, Figure 5). 


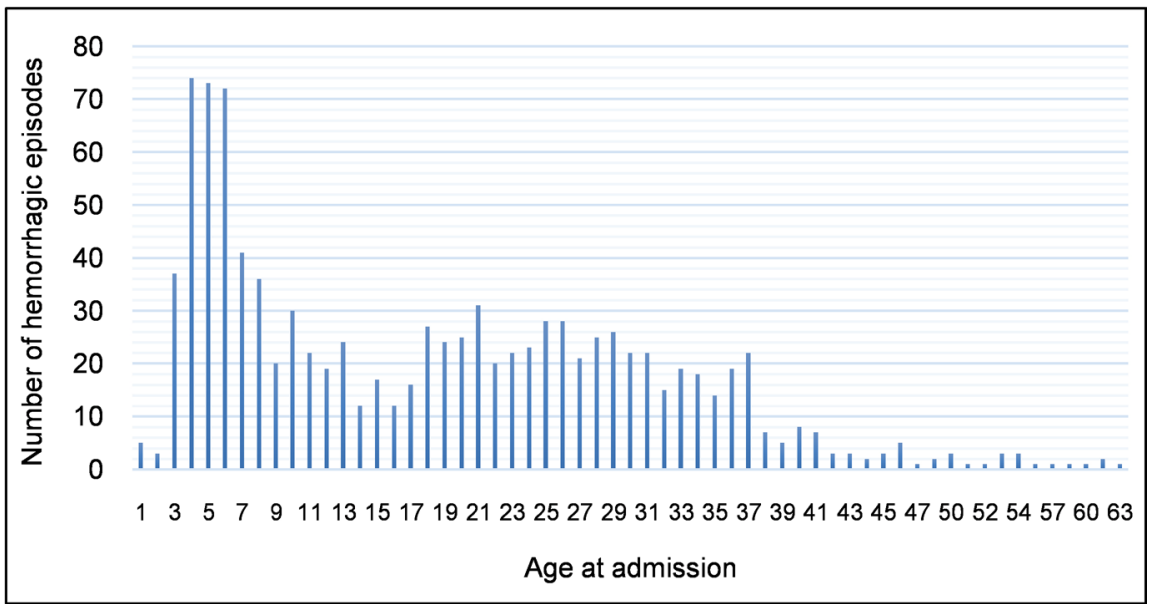

Figure 4. The frequency of $\mathrm{POH}$ admitted cases by the age.

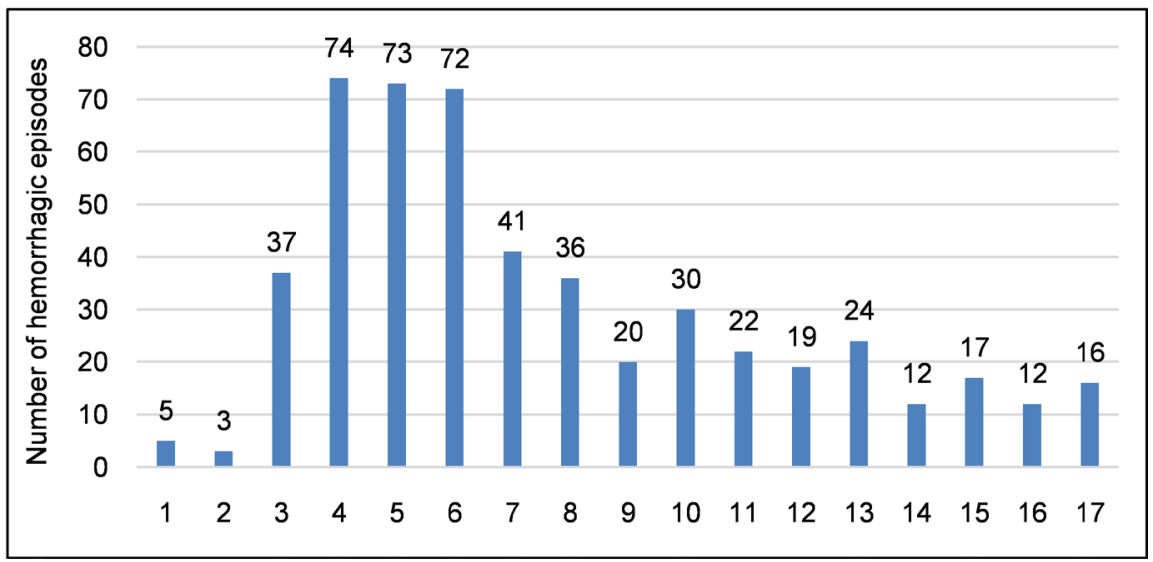

Figure 5. The frequency of $\mathrm{POH}$ admitted cases in pediatric age group.

\section{Discussion}

In this retrospective cohort study, we aimed to characterize the associations between seasonal factors and $\mathrm{POH}$ as well as patient-related factors. There are no clear data that report significant relationship of seasonal factors effect on the incidence of hemorrhage following ENT procedures.

In a study which was published recently studying Secondary Post-Tonsillectomy Hemorrhage (SPTH) in children from our institution, the incidence of bleeding among pediatrics was $2.4 \%$ which corresponds to the worldwide results, and the average time of SPTH was 7.7 days $(\mathrm{SD}= \pm 3.4)$ [15]. It is a fact that incidence of upper respiratory tract infections (URTIs), common cold and influenza exhibits seasonal fluctuations as respiratory illness peaks during the winter months. Because of that, there is a general belief that hemorrhage is more common in winter months. Some studies have also shown a decrease in coagulation in colder temperatures [16] [17] [18]. Several studies have examined the relationship between season, temperature, humidity and the presentation of epistaxis or posttonsillectomy bleeding. Some reports signify the increase in incidence of postoperative hemorrhage cases in winter [19] [20], Eski, et al. reported that season 
and temperature had a significant influence on SPTH cases with a significant increase during the winter months $(\mathrm{p}<0.05)$ [19]. Alobaid, et al, also reported increased risk of SPTH in winter month [21] (Table 3). They concluded that in patient at high risk of bleeding, avoiding tonsillectomy during winter months my reduce the probability of secondary hemorrhage [19].

On the other hand, Kwok MM et al. and Lee, M.S.W. et al. reported higher incidence of post-operative bleeding during spring [22] [23] (Table 3). However, Lee, M.S.W. et al. reported a negative correlation between mean air temperature and humidity rate and secondary hemorrhage and suggested that performing tonsillectomy in warmer weather with higher water vapor pressure reduced the incidence of secondary hemorrhage [22]. In another cohort study, 941 patients were analyzed of which 7.7\% had post-tonsillectomy bleeding. However, Cadd, et al. found no significant difference in the rates of bleeding between dry and wet seasons ( $\mathrm{p}=0.279$ ), and nocorrelation between other meteorological factors like temperature $(\mathrm{p}=0.74)[24]$. There was a strong negative correlation between temperature and number of epistaxis cases, epistaxis rates showed a decrease in cases in summer season as compared to all other seasons which demonstrated similar rates [25]. Some reports have found an increased risk of post-tonsillectomy hemorrhage for warmer months between May to July [26] [27] [28], and highlighted the temperature at the day of the operation as a risk factor of SPTH within 3 days postoperatively, which corresponds to what we found in our study.

The largest series published in the literature on post-tonsillectomy hemorrhage was a study which included 256,799 cases. This study found that hemorrhage varied by month and season, hemorrhage peaked during winter and summer, but rates were significantly higher in the winter [20].

Our results showed an increasing tendency for post-operative hemorrhage in summer, followed by winter, autumn, and then spring, and this relationship was statistically significant. Other studies examined the association between various climatic parameters and hemorrhage but reported contradictory results that do not support the view of a relationship between hemorrhage and temperature or seasonal variation [11] [29] [30]. Therefore, it is not reasonable to make seasonal choices for the performance of surgery.

Table 3. Comparison of our data to international rates of post-operative hemorrhage in each season.

\begin{tabular}{ccccc}
\hline Study name & Autumn POH & Summer POH & Spring POH & Winter POH \\
\hline Our data & $232(22.5 \%)$ & $\mathbf{3 4 8 ( 3 3 . 7 \% )}$ & $219(21.2 \%)$ & $233(22.6 \%)$ \\
E. Eski., et al. [18] & $8(11.3 \%)$ & $19(26.8 \%)$ & $15(21.1 \%)$ & $29(40.8 \%)$ \\
Kwok, M.M., et al. 2018 [22] & $21(1.67 \%)$ & $18(1.43 \%)$ & $\mathbf{3 2 ( 2 . 5 4 \% )}$ & $16(1.27 \%)$ \\
Alobaid, F., et al. $2019[20]$ & $1(0.9 \%)$ & $2(1.5 \%)$ & $5(3.2 \%)$ & $7(6 \%)$ \\
Lee, M.S.W., et al. $2005[21]$ & $8(22 \%)$ & $5(13.5 \%)$ & $14(38 \%)$ & $10(27.02 \%)$ \\
\hline
\end{tabular}


The fact that this cohort study is from a single institution may be considered as a limitation for our results. Nevertheless, this study was of a relatively large sample size of more than 1000 patients. Unlike case control and cross-sectional studies, the employed study design allows for reliable investigation of the incidence and possible association of multiple factors with post-operative hemorrhage. The present study showed that seasonal variation does significantly affect the rate of post-operative hemorrhage, which is consistent with some of the previous literature, therefore we recommend the timing of the procedure to be taken into consideration.

\section{Conclusion}

The incidence of hemorrhage showed monthly and seasonal variations. This is clearly a multi-factorial problem. However, in patients at high risk of bleeding, consideration should be given to performing surgeries at a time of year of lower incidence.

\section{Financial Support}

The authors reported no conflict of interest or any affiliation or financial involvement with organizations or entities with a direct financial interest in the subject matter or materials discussed in the manuscript to disclose. No funding was received for this work from any organization.

\section{Acknowledgements}

The authors would like to thank Dr. Amer Jebril Khalaf a doctor in statistics and Lecturer at Family \& Community Medicine Department at Arabian gulf University, Bahrain, for his guidance in performing the statistical analysis of all data.

\section{Criteria of Author Inclusion}

As stated by the international committee of medical journal editors (ICMJE); contribution to the conception or design of the work, or acquisition, analysis, or interpretation of data for the work, and drafting the work or revising it critically for important intellectual content, and final approval of the version to be published, and agreement to be accountable for all aspects of the work in ensuring that questions related to the accuracy or integrity of any part of the work are appropriately investigated and resolved.

The manuscript has been read and approved by all the authors, the requirements for authorship have been met, and each author believes that the manuscript represents honest work.

\section{Conflicts of Interest}

The authors declare no conflicts of interest regarding the publication of this paper. 


\section{References}

[1] Derkay, C.S. (1993) Pediatric Otolaryngology Procedures in the United States: 1977-1987. International Journal of Pediatric Otorhinolaryngology, 25, 1-12. https://doi.org/10.1016/0165-5876(93)90004-M

[2] Williams, R.G. (1967) Haemorrhage Following Tonsillectomy and Adenoidectomy. The Journal of Laryngology \& Otology, 81, 805-808. https://doi.org/10.1017/S0022215100067712

[3] Pratt, L.W. (1970) Tonsillectomy and Adenoidectomy: Mortality and Morbidity. Transactions - American Academy of Ophthalmology and Otolaryngology, 74, 1146-1154.

[4] Mandal, S., Ashwin, N.T., Sharma, A. and Bhardwaj, R. (2020) Trans-Septal Suturing versus Merocel Nasal Packing: A Post Septoplasty Comparison. Indian Journal of Otolaryngology and Head \& Neck Surgery, 72, 1-6. https://doi.org/10.1007/s12070-020-02013-6

[5] Elinder, K., Söderman, A.C., Stalfors, J. and Knutsson, J. (2016) Factors Influencing Morbidity after Paediatric Tonsillectomy: A Study of 18,712 Patients in the National Tonsil Surgery Register in Sweden. European Archives of Oto-Rhino-Laryngology, 273, 2249-2256. https://doi.org/10.1007/s00405-016-4001-x

[6] Ikoma, R., Sakane, S., Niwa, K., Kanetaka, S., Kawano, T. and Oridate, N. (2014) Risk Factors for Post-Tonsillectomy Hemorrhage. Auris Nasus Larynx, 41, 376-379. https://doi.org/10.1016/j.anl.2014.02.007

[7] Kim, M.K., Lee, J.W., Kim, M.G., Ha, S.Y., Lee, J.S. and Yeo, S.G. (2012) Analysis of Prognostic Factors for Postoperative Bleeding after Tonsillectomy. European Archives of Oto-Rhino-Laryngology, 269, 977-981.

https://doi.org/10.1007/s00405-011-1697-5

[8] Tomkinson, A., Harrison, W., Owens, D., Harris, S., McClure, V. and Temple, M. (2011) Risk Factors for Postoperative Hemorrhage Following Tonsillectomy. Laryngoscope, 121, 279-288. https://doi.org/10.1002/lary.21242

[9] Perkins, J.N., Liang, C., Gao, D., Shultz, L. and Friedman, N.R. (2012) Risk of Post-Tonsillectomy Hemorrhage by Clinical Diagnosis. Laryngoscope, 122, 2311-2315. https://doi.org/10.1002/lary.23421

[10] Moral, S.D., Barlin, A.K. and Acuin, J.M. (2010) Clinical Profile of Post-Tonsillectomy Bleeding: A 30-Month Institutional Review. Philippine Journal of Otolaryngology Head and Neck Surgery, 25, 14-17. https://doi.org/10.32412/pjohns.v25i2.621

[11] Nami Saber, C. and Klug, T.E. (2020) Post-Operative Haemorrhage after Acute Bilateral Tonsillectomy in Patients with Peritonsillar Abscess: Prevalence, Treatment, Risk Factors, and Side of Bleeding. Acta Oto-Laryngologica, 140, 66-71. https://doi.org/10.1080/00016489.2019.1682189

[12] Giger, R., Landis, B.N. and Dulguerov, P. (2005) Hemorrhage Risk after Quinsy Tonsillectomy. Otolaryngology_Head and Neck Surgery, 133, 729-734. https://doi.org/10.1016\%2Fj.otohns.2005.07.013

[13] Höppe, P. (1997) Aspects of Human Biometerology in Past, Present and Future. International Journal of Biometeorology, 40, 19-23. https://doi.org/10.1007/BF02439406

[14] Chowdhury, K., Tewfik, T.L. and Schloss, M.D. (1988) Post-Tonsillectomy and Adenoidectomy Hemorrhage. Journal of Otolaryngology, 17, 46-49.

[15] Abdeen, Z.A., Husain, W.A., Mandeel, A.Q. and Almoosawi, S.M. (2020) Post Tonsillectomy Bleeding among Children in a Tertiary Hospital in the Kingdom of Ba- 
hrain: Two Years Experience. International Journal of Otolaryngology and Head \& Neck Surgery, 9, 209-218. https://doi.org/10.4236/ijohns.2020.96024

[16] Sutor, A., Bowie, E.W. and Owen, C. (1970) Effect of Cold on Bleeding: Hippocrates Vindicated. Lancet, 296, 1084. https://doi.org/10.1016/S0140-6736(70)90314-4

[17] Wolberg, A.S., Meng, Z.H., Monroe III, D.M. and Hoffman, M. (2004) A Systematic Evaluation of the Effect of Temperature on Coagulation Enzyme Activity and Platelet function. Journal of Trauma: Injury, Infection, and Critical Care, 56, 1221-1228. https://doi.org/10.1097/01.TA.0000064328.97941.FC

[18] Rundgren, M. and Engström, M. (2008) A Thromboelastometric Evaluation of the Effects of Hypothermia on the Coagulation System. Anesthesia \& Analgesia, 107, 1465-1468. https://doi.org/10.1213/ane.0b013e31817ee955

[19] Eski, E., Dogan, I. and Yilmaz, I. (2011) Seasonal Variation of Secondary Post Tonsillectomy Hemorrhage Rates. B-ENT, 7, 165-168.

[20] Chadha, N.K. (2007) Tonsillectomy Return-to-Theatre Rates Demonstrate a Monthly and Seasonal Variation: An Analysis of 256,799 Patients. The Journal of Laryngology \& Otology, 121, 1088-1093. https://doi.org/10.1017/S0022215107005622

[21] Alobaid, F., Alhuthaily, K., Arafat, A., Alhazmi, B. and Almegbel, M. (2019) Seasonal Variation Effect on the Incidence of Secondary Post-Tonsillectomy Bleeding in Saudi Arabia: A Tertiary Centre Experience. Journal of Otolaryngology, 2, Article No. 201.

[22] Lee, M.S., Montague, M.L. and Hussain, S.S. (2005) The Influence of Weather on the Frequency of Secondary Post-Tonsillectomy Haemorrhage. The Journal of Laryngology \& Otology, 119, 894-898. https://doi.org/10.1258/002221505774783548

[23] Cadd, B., Rogers, M., Patel, H. and Crossland, G. (2015) (Ton)Silly Seasons? Do Atmospheric Conditions Actually Affect Post-Tonsillectomy Secondary Haemorrhage Rates? The Journal of Laryngology \& Otology, 129, 702-705. https://doi.org/10.1017/S0022215115001292

[24] Kwok, M.M., Subramaniyan, M., Rimmer, J. and Karahalios, A. (2018) Post-Tonsillectomy Haemorrhage in Australia-A Multivariable Analysis of Risk Factors. Australian Journal of Otolaryngology, 1, Article No. 2. https://doi.org/10.21037/ajo.2018.01.06

[25] Sowerby, L.J., DeSerres, J.J., Rudmik, L. and Wright, E.D. (2014) Role of Season, Temperature and Humidity on the Incidence of Epistaxis in Alberta, Canada. Journal of Otolaryngology - Head \& Neck Surgery, 43, Article No. 10. https://doi.org/10.1186/1916-0216-43-10

[26] Roberts, C., Jayaramachandran, S. and Raine, C.H. (1992) A Prospective Study of Factors which May Predispose to Post-Operative Tonsillar fossa Haemorrhage. Clinical Otolaryngology \& Allied Sciences, 17, 13-17. https://doi.org/10.1111/j.1365-2273.1992.tb00980.x

[27] Collison, P.J. and Mettler, B. (2000) Factors Associated with Post-Tonsillectomy Hemorrhage. Ear, Nose \& Throat Journal, 79, 640-649. https://doi.org/10.1177\%2F014556130007900820

[28] Schroeder Jr., W.A. (1995) Post Tonsillectomy Hemorrhage: A Ten-Year Retrospective study. Missouri Medicine, 92, 592-595.

[29] Bray, D., Giddings, C.E., Monnery, P. and Eze, N. (2005) Epistaxis: Are Temperature and Seasonal Variations True Factors in Incidence? The Journal of Laryngology \& Otology, 119, 724-726. https://doi.org/10.1258/0022215054798032 
[30] Civelek, S., Sayın, İ., HelbestAkgul, Y., Kalkavan, C.S. and Turgut, S. (2009) The Relationship between the Weather Variables and Secondary Post-Tonsillectomy Haemorrhage. Turkish Archives of Otorhinolaryngology, 47, 63-68. 